\title{
Hubungan Paritas Dengan Berat Badan Lahir Rendah (BBLR)
}

\author{
Elis Fatmawati 1); Dwi Retno Wati2); Justina Tehuayo3);Lidia Aditama Putri ${ }^{4}$ \\ 1) 2) Pendidikan Profesi Bidan, STIKes Husada Jombang, Jombang 61481, Indonesia \\ 2) Pendidikan Sarjana Kebidanan/STIKes Husada Jombang, Jombang 61481, Indonesia \\ 4) Prodi Kebidanan, Universitas Muhammadiyah Gresik, Gresik 61111, Indonesia \\ Corresponding Author: Elis Fatmawati \\ E-mail: elis.emi.farida@gmail.com
}

\section{INFORMASI ARTIKEL}

\section{Riwayat Artikel:}

Submit : 05-10-2021

Revisi : 15-10-2021

Diterima : 07-11-2021

Publikasi : 30-11-2021

DOI :

http://dx.doi.org/10.30587/ijmt.v1i1.3419

\section{Keywords: \\ Parity; \\ Low Birth Weight; \\ $L B W$;}

Kata Kunci:

Paritas;

Berat Badan Lahir Rendah;

BBLR;

\begin{abstract}
One of the indicators that determine a country's health status is the high and low number of the Infant Mortality Rate (IMR). Meanwhile, the incidence of Low Birth Weight (LBW) is one of the main determining factors that contribute to the Infant Mortality Rate (IMR). Many factors cause an increase in the number of IMR, one of which is parity. This study aims to determine the relationship between parity and low birth weight (LBW) in Cendrawasih Dobo Hospital, Aru Islands Regency.

This study uses analytical research with a "retrospective" research design. The dependent variable is parity and the independent variable is $L B W$. The population in this study were all mothers who had LBW in Cendrawasih Dobo Hospital, Aru Islands Regency in 2020 as many as 42 mothers with LBW babies. Sampling using a total sampling technique. The study was conducted from July 1 to August 31, 2020, using secondary data, and analyzed using the Spearman Ranks statistical test.

The results showed that almost half of the primiparous mothers gave birth to LBW babies, namely 15 babies (35.7\%) and most of the multipara mothers gave birth to 22 LBW babies (52.4\%). Based on the results of statistical tests using Spearman Rho with $=0.05$ ) the value of count $(0.470)>r$ table $(0.257)$ then $\mathrm{H} 1$ is accepted, $\mathrm{HO}$ is rejected, this means that there is a parity relationship with low birth weight (LBW).

There were that not only high parity has the potential for LBW births, but even low parity has the potential to occur LBW births considering that there are many factors that can influence it, not only in terms of maternal parity. Health agencies can make efforts to prevent the occurrence of $L B W$ by improving the quality of health services.
\end{abstract}

\footnotetext{
ABSTRAK

Salah satu indikator penentu derajat kesehatan suau negara adalah tinggi rendahnya jumlah Angka Kematian Bayi (AKB). Sedangkan, kejadian Berat Badan Lahir Rendah (BBLR) merupakan salah satu faktor penentu utama yang menyumbang Angka Kematian bayi (AKB). Banyak faktor yang menyebabkan terjadinya peningkatan jumlah AKB, salah satunya adalah paritas. Penelitian ini bertujuan untuk mengetahui hubungan paritas dengan berat badan lahir rendah (BBLR) Di RSUD Cendrawasih Dobo Kabupaten Kepualauan Aru.

Penelitian ini menggunakan penelitian analitik dengan desain penelitian "retrospektif". Variabel dependen adalah paritas dan variabel independen adalah BBLR. Populasi pada penelitian ini adalah seluruh ibu yang mempunyai BBLR di Di RSUD Cendrawasih Dobo Kabupaten Kepualauan Aru tahun 2020 sebanyak 42 ibu dengan bayi BBLR,. Pengambilan sampel menggunakan teknik total sampling. Penelitian dilakukan pada tanggal 1
} 
Juli sampai 31 Agustus 2020 menggunakan data sekunder, dan dianalisis menggunakan uji statistik Spearman Ranks.

Hasil penelitian menunjukan hampir setengahnya ibu primipara melahirkan bayi BBLR yaitu sebanyak 15 bayi ( $35,7 \%$ ) dan sebagian besar ibu multipara melahirkan bayi BBLR sebanyak 22 orang $(52,4 \%)$. Berdasarkan hasil uji statistik menggunakan Spearman Rho dengan $\mathrm{a}=$ 0,05)didapatkan nilai $r_{\text {hitung }}(0,470)>r$ tabel $(0,257)$ maka $\mathrm{H} 1$ diterima, $\mathrm{H} 0$ ditolak, hal ini berarti ada hubungan paritas dengan berat badan lahir rendah (BBLR).

Kesimpulan dari penelitian ini menunjukkan bahwa tidak hanya paritas tinggi saja yang berpotensi terjadinya kelahiran BBLR namun paritas rendahpun juga berpotensi terjadinya kelahiran BBLR mengingat banyak faktor yang dapat mempengaruhinya bukan hanya dari segi paritas ibu saja. Instansi kesehatan dapat melakukan upaya pencegahan terjadinya BBLR dengan cara meningkatkan kualitas mutu layanan kesehatan

\section{PENDAHULUAN}

Pembangunan kesehatan sebagai salah satu upaya Pembangunan Nasional bertujuan untuk mencapai suatu kemauan, kesadaran, dan kemampuan setiap penduduk untuk hidup ehat sehingga mampu mewujudkan tingkat kesehatan yang optimal. Sebenarnya, ada berbagai faktor penentu kualitas derajat kesehatan suatu negara, salah satunya adalah faktor jumlah kematian bayi. Tinggi rendahnya Angka Kematian Bayi (AKB) paling banyak dipengaruhi oleh kelahiran berat badan rendah atau yang disebut BBLR (Berat Badan Lahir Rendah). Kemudian, BBLR sendiri erat hubungannya pula dngan paritas ibu atau jumlah anak yang dilahirkan ibu.

Prevalensi BBLR menurut World Health Organization (WHO) diperkirakan mencapai 6,2\% dari seluruh kelahiran di dunia pada tahun 2018. Kejadian BBLR ini sering terjadi ada negaranegara yang sedang berkembang dan/atau negara dengan tingkat sosial ekonomi yang rendah (DEPKES RI, 2001). Negara yang ada di kawasan Asia Tenggara menyumbang prosentasi 27\% dari seluruh kejadian BBLR didunia. Sedangkan di Indonesia, menurut data terakhir dari tahun 2010 didapatkan bahwa preosentase kejadian BBLR sebesar 11,1\%, dimana hal ini masih tertinggal dari Thailand dan Vietnam yang masih berkisar 6,6\% dan 5,3\% (UNICEF Indonesia, 2019).
Secara nasional, angka kejadian BBLR tampaknya bervariasi. Namun, berdasarkan survei lanjutan dari SDKI ditemukan bahwa insiden BBLR terjadi sekitar 7,5\% (Badan Pusat Statistik, Badan Koordinasi Keluarga Berencanan Nasional, Departemen Kesehatan, \& Macro International, 2013). Sedangkan, jika dilihat berdasarkan daerah, terjadi peningkatan insiden BBLR di Maluku sebesar 2,7\% dari tahun 2018 yang semula hanya berkisar $8 \%$ menjadi sekitar 10,7\% pada tahun 2019 (Balitbang Kemkes RI, 2019).

Data dari Laporan Bulanan 3 (LB3) Kesehatan Ibu dan Anak Dinas Kesehatan Maluku pada tahun 2019 mencatat bahwa presentase kejadian BBLR di Maluku menyentuh angka 1,58\% (Dinkes Maluku, 2019). Sedangkan, data dari Rumah Sakit Umum (RSUD) Cendrawasih Dobo Maluku mencatat bahwa dari 654 kelahiran bayi, sebanyak 92 bayi lahir dengan berat badan rendah sepanjang tahun 2018.

Berbagai upaya untuk meningkatkan kualitas sumber daya manusia sejak dalam kandungan telah dilakukan, salah satunya dengan upaya penapisan ibu hamil risiko tinggi. Sejatinya, faktor penyebab terjadinya BBLR adalah multifaktor. Prematuritas merupakan faktor yang paling banyak menyebabkan terjadinya BBLR. Selain itu, faktor karakteristik ibu juga mempengaruhi kerjadian BBLR, diantaranya adalah paritas, usia ibu, dan lain lain. Faktor plasenta dan janin seperti 
kehamilan kembar, penyakit vaskuler, dan sebagainya juga turut menyumbang angka kejadian BBLR (Evasari \& Nurmala, 2016; Pantiawati, 2010). Kematian perinatal dan kejadian BBLR pada umumnya akan meningkat sejalan dengan meningkatnya pula paritas ibu, apalagi jika ibu telah melahirkan lebih dari 3 kali. Hal ini disebabkan karena ibu dengan paritas tinggi pada umumnya akan menimbulkan terjadinya gangguan pada uterus terutama gangguan fungsi pembuluh dara uterus. Ibu dengan paritas tinggi memiliki risiko $4 \mathrm{x}$ lebih besar mengalami kejadian BBLR kurang dari 2500 gram (Bambang, Khasanah, \& Khoirotul, 2011).

Kerusakan dinding pembuluh darah rahim kemungkinan dapat terjadi pada kehamilan yang berulang-ulang. Kerusakan dinding pembuluh darah tersebut akan bepengaruh terhadap transfer nutrisi dari sawar plasenta ke janin pada kehamilan ibu yang berikutnya. Akibat dari terganggunya transfer nutrisi tersebut dapat menyebabkan terjadinya IUGR (gangguan pertumbuhan dan perkembangan janin) sehingga janin dapat lahir dengan berat badan yang rendah, sedangkan pada ibu dapat menyebabkan terjadinya atona uteri (gangguan kontraksi rahim saat melahirkan) (Winkjosastro, 2008; Wong, D. L., Hockenberry, M. E., Wilson, D., Winkelstein, M. \& Schwartz, 2009).

Alasan lainnya yang dikemukakan oleh Bambang et al. (2011) yaitu kejadian BBLR bisa disebabkan oleh adanya jaringan parut akibat kehamilan yang sebelumnya sehingga hal ini dapat menyebabkan plasenta tidak dapat melekat dengan adekuat. Plasenta yang tidak melekat dengan sempurna ini dapat menyebabkan terhambatnya nutrisi dari ibu ke janin. Oleh karena itu, kejadian BBLR cenderung lebih sering terjadi pada ibu dengan paritas yang tinggi dibandingkan dengan partitas yang rendah.

Mengingat besarnya risiko yang
disebabkan oleh kejadian BBLR, maka melakukan penyuluhan kepada masyarakat adalah hal yang dapat dilakukan untuk meminimalisir risiko ini. Pemberian penyuluhan dapat dilakukan kepada ibu hamil untuk mengatur jarak kehamilan dengam mengikuti program KB, melakukan penyuluhan tentang gizi seimbang selama hamil, dan sebagainya.

Berdasarkan latar belakang yang telah peneliti uraikan di atas dan fenomena yang ada, maka peneliti tertarik dan bermaksud akan melakukan penelitian dengan tujuan untuk mengetahui hubungan paritas dengan berat badan lahir rendah (BBLR).

\section{METODE}

Penelitian ini menggunakan penelitian analitik dengan desain penelitian “retrospektif". Penelitian ini adalah penelitian yang berusaha melihat kebelakang (backward looking), artinya pengumpulan data dimulai dari efek atau akibat yang telah terjadi. Kemudian dari efek tersebut ditelusuri kebelakang tentang penyebabnya atau variabel-variabel yang mempengaruhi akibat tersebut. Dengan kata lain, dalam penelitian retrospektif ini berangkat dari dependent variables, kemudian dicari independent variable-nya (Notoatmodjo, 2010).

Populasi pada penelitian ini adalah semua ibu yang melahirkan bayi BBLR di di Ruangan Kebidanan RSUD Cendrawassih Dobo tahun 2020 yaitu sejumlah 42 orang. Sampel yang digunakan adalah keseluruhan dari populasi yaitu ibu yang melahirkan bayi BBLR di Ruangan Kebidanan RSUD Cendrawasih Dobo pada periode bulan Januari sampai dengan September 2020 yang berjumlah 42 orang. Teknik pengambilan yang digunakan pada penelitian adalah Nonprobability dengan jenis total sampling yaitu dengan mengambil semua anggota populasi menjadi sampel (Hidayat, 2010).

Variabel independen dalam penelitian ini adalah paritas. Sedangkan variable dependen adalah berat badan lahir rendah. Lokasi penelitian ini dilakukan di Ruangan Kebidanan RSUD Cendrawasih Dobo Kabupaten Kepulauan Aru. Waktu penelitian ini dilaksanakan pada 
bulan Oktober 2020 dengan melihat data bulan Januari sampai dengan September 2020.

Penelitian ini bertujuan mengetahui hubungan paritas dengan BBLR di Ruangan Kebidanan RSUD Cendrawasih Dobo tahun 2020 tahun, maka analisis statistik yang digunakan adalah Correlation Rank Spearman, dengan bantuan SPSS 20.0 dengan signifikansi a=0,05.

\section{HASIL PENELITIAN}

Hasil penelitian disajikan dalam dua bagian yaitu data umum dan data khusus. Data umum dimuat karakteristik umur, pendidikan, pekerjaan dan riwayat patologi. Sedangkan data khusus terdiri dari paritas dan kejadian bayi berat badan lahir rendah serta tabel silang yang menggambarkan hubungan paritas dengan bayi berat badan lahir rendah di Ruangan Kebidanan RSUD Cendrawasih Dobo Tahun 2020.

\section{Data Umum}

Tabel 1. Distribusi Frekuensi Karakteristik ResponDen Berdasarkan Umur Ibu Yang Melahirkan Bayi BBLR di Ruang Kebidanan RSUD Cendrawasih Dobo

\begin{tabular}{cccc}
\hline No & Umur & Frekuensi & Presentase \\
\hline 1 & $<20$ tahun & 5 & 11,9 \\
2 & $20-35$ tahun & 20 & 47,6 \\
3 & $>35$ tahun & 17 & 40,5 \\
\hline & Jumlah & 42 & 100 \\
\hline
\end{tabular}

Sumber: Data Primer, 2020

Berdasarkan tabel 1 diatas menunjukkan bahwa hampir setengah dari responden $(47,6 \%)$ yang berumur 20-35 tahun.

Tabel 2. Distribusi Frekuensi Karakteristik Responden Berdasarkan Pendidikan Ibu Yang Melahirkan Bayi BBLR di Ruang Kebidanan RSUD Cendrawasih Dobo

\begin{tabular}{clcc}
\hline No & Pendidikan & Frekuensi & Presentase \\
\hline 1 & Lulus SD & 7 & 16,7 \\
2 & SMP & 13 & 31,0 \\
3 & SMA & 12 & 28,6 \\
4 & Perguruan Tinggi & 10 & 23,8 \\
\hline \multicolumn{2}{r}{ Jumlah } & 42 & 100 \\
\hline
\end{tabular}

Sumber: Data Primer, 2020
Berdasarkan tabel 2 diatas menunjukkan bahwa hampir setengah dari responden berpendidikan SMP (31,0\%).

Tabel 3. Distribusi Frekuensi Karakteristik Responden Berdasarkan Pekerjaan Dari Ibu Yang Melahirkan Bayi BBLR di Ruang Kebidanan RSUD Cendrawasih Dobo

\begin{tabular}{clcc}
\hline No & \multicolumn{1}{c}{ Pendidikan } & Frekuensi & Presentase \\
\hline 1 & Karyawan Swasta & 14 & 33,3 \\
2 & Wiraswasta & 7 & 16,7 \\
3 & PNS & 3 & 7,1 \\
4 & Ibu rumah tangga & 18 & 42,9 \\
\hline \multicolumn{2}{r}{ Jumlah } & 42 & 100
\end{tabular}

Sumber: Data Primer, 2020

Berdasarkan tabel 3 diatas menunjukkan bahwa hampir setengah dari responden bekerja sebagai ibu rumah tangga (42,9\%).

Tabel 4. Distribusi Frekuensi Karakteristik Responden Berdasarkan Kondisi Patologis Penyerta Dari Ibu Yang Melahirkan Bayi BBLR di Ruang Kebidanan RSUD Cendrawasih Dobo

\begin{tabular}{clcc}
\hline No & Kondisi patologis & Frekuensi & Presentase \\
\hline 1 & Sehat & 31 & 73.8 \\
2 & DM & 3 & 7.1 \\
3 & Hipertensi & 1 & 2.4 \\
4 & PPI & 3 & 7.1 \\
5 & PEB & 4 & 9.5 \\
\hline \multicolumn{2}{r}{ Jumlah } & 42 & 100
\end{tabular}

Sumber: Data Primer, 2020

Berdasarkan tabel 4 diatas menunjukkan bahwa hampir seluruh dari responden dalam kondisi sehat $(73,8 \%)$.

\section{Data Khusus}

Tabel 5. Distribusi Frekuensi Paritas Ibu Yang Melahirkan Bayi BBLR di Ruang Bersalin RSUD Cendrawasih Dobo

\begin{tabular}{cccc}
\hline No & Paritas & Frekuensi & Presentase \\
\hline 1 & Primipara & 15 & 35,7 \\
2 & Multipara & 12 & 52,4 \\
3 & Grande Multipara & 5 & 11,9 \\
\hline & Jumlah & 42 & 100 \\
\hline
\end{tabular}

Sumber: Data Primer, 2020

Berdasarkan tabel 5 diatas menunjukkan bahwa sebagian besar $(52,4 \%)$ ibu dengan primipara melahirkan bayi BBLR. 
Tabel 6. Distribusi frekuensi berat badan lahir di Ruang Bersalin RSUD Cendrawasih Dobo

\begin{tabular}{cccc}
\hline No & Berat Lahir & Frekuensi & Presentase \\
\hline 1 & BBLR & 39 & 92,9 \\
2 & BBLSR & 3 & 7,1 \\
3 & BBLER & 0 & 0 \\
\hline & Jumlah & 42 & 100 \\
\hline
\end{tabular}

Sumber: Data Primer, 2020
Berdasarkan tabel 6 diatas menunjukkan bahwa hampir seluruhnya (92,9\%) bayi lahir dengan BBLR.

Tabel 7. Tabulasi silang paritas dengan berat badan lahir di Ruang RSUD Cendrawasih Dobo

\begin{tabular}{|c|c|c|c|c|c|c|c|c|}
\hline \multirow{3}{*}{ Paritas } & \multicolumn{6}{|c|}{ Klasifikasi Berat Badan Lahir Rendah Pada BBL } & \multirow{2}{*}{\multicolumn{2}{|c|}{ Total }} \\
\hline & \multicolumn{2}{|c|}{ BBLR } & \multicolumn{2}{|c|}{ BBLSR } & \multicolumn{2}{|c|}{ BBLER } & & \\
\hline & $\mathrm{F}$ & $\%$ & $\mathrm{~F}$ & $\%$ & $\mathrm{~F}$ & $\%$ & $\mathrm{~F}$ & $\%$ \\
\hline Primipara & 15 & 35,7 & 0 & 0 & 0 & 0 & 15 & 35,7 \\
\hline Multipara & 22 & 52,4 & 0 & 0 & 0 & 0 & 22 & 52,4 \\
\hline Grandemultipara & 2 & 4,8 & 3 & 7,1 & 0 & 0 & 5 & 11,9 \\
\hline
\end{tabular}

Berdasarkan tabel 7 diatas menunjukkan bahwa hampir setengahnya ibu primipara melahirkan bayi BBLR yaitu sebanyak 15 bayi ( $35,7 \%)$ dan sebagian besar ibu multipara melahirkan bayi BBLR sebanyak 22 orang $(52,4 \%)$ dan sebaian kecil ( 7,1\%) ibu Grande multipara yang melahirkan bayi dengan BBLSR. Menurut hasil uji statistik menggunakan Spearman Rho dengan signifikansi 95\% $(a=0,05)$ didapatkan nilai $r_{\text {hitung }}(0,470)$ yang berarti lebih besar daripada nilai $r$ tabel $(0,257)$ maka $\mathrm{H} 1$ diterima, $\mathrm{HO}$ ditolak, hal ini berarti ada hubungan paritas dengan berat badan lahir rendah (BBLR) di Ruang Bersalin RSUD Cendrawasih Dobo Tahun 2020 Januari - Juli Tahun 2020.

\section{PEMBAHASAN}

\section{Paritas}

Berdasarkan hasil penelitian diatas menunjukkan bahwa sebagian besar $(52,4 \%)$ ibu dengan primipara melahirkan bayi BBLR. Grande multipara yang melahirkan bayi dengan BBLR.

Hasil penelitian ini sesuai dengan teori yang ada yaitu riwayat jumlah anak lebih dari 4 dapat menyebabkan gangguan pertumbuhan janin sehingga dapat mengakibatkan BBLR dan perdarahan saat melahirkan karena keadaan rahim biasanya sudah lemah hal itu diperberat dengan Keadaan sosial antara lain golongan sosial ekonomi rendah dan perkawinan yang tidak sah karena Ibu-ibu yang terlalu muda seringkali secara fisik dan emosional belum matang, selain pendidikan yang juga pada umumnya masih rendah (Bambang et al., 2011; Wong, D. L., Hockenberry, M. E., Wilson, D., Winkelstein, M. \& Schwartz, 2009).

Kelahiran BBRL lebih tinggi pada ibu-ibu usia dengan usia tua, hal ini disebabkan karena kondisi badan dan kesehatan ibu mulai menurun (Bambang et al., 2011). Sedangkan, Winkjosastro (2008) mengatakan bahwa ibu dengan paritas lebih dari 4 memiliki risiko kematian maternal dan neonatal yang lebih tinggi.

Salah satu efek dari penurunan kondisi kesehatan pada sistem reproduksi yang mengalami proses degenerative dapat menyebabkan sklerosis pembuluh darah arteri kecil dan arteriole miometrium menyebabkan aliran darah ke endometrium terhambat, hal ini dapat menyebabkan terganggunya pengaliran nutrisi dari ibu ke janin dan menyebabkan IUGR. Penurunan kondisi kesehatan reproduksi ini umumnya terjadi pada wanita dengan usia lebih dari 35 tahun (Prawirohardjo, 2010).

Dari paritas dengan usia $<20$ tahun adalah secara anatomi reproduksi serta kematangan psikologi masih prematur. Sehingga tak jarang ibu dengan primipara melahirkan bayi 
dengan berat badan lahir rendah. Begitu juga dengan ibu dengan grandemulti para dan usia lebih dari 35 tahun, sistem reproduksinya mengalami penurunan baik secara anatomi maupun fisiologi sehingga perlengkatan placenta kurang baik yang mengakibatkan suplai asupan makanan dan oksigen tidak sampai dengan baik ke janin yang akhirnya menyebabkan bayi lahir dengan BBLR.

Dampak dari ibu yang hamil di bawah usia 20 tahun dimana secara psikologis belum matang. Sedangkan pada ibu dengan usia lebih dari 35 tahun adalah menurunnya fungsi organ reproduksi sehingga angka kejadian BBLR kemungkinan besar terjadi.Dengan kejadian BBLR yang cukup tinggi di Rumah sakit Kristen Mojowarno maka ada beberapa upaya untuk menanggulanginya yaitu dengan diadakannya ANC terpadu bersama dokter spesialis obgyn. Dalam kebutuhan gizi dapat berkonsultasi dengan dietisien bagaiman cara menajga kesehatan dan kesejahteraan janin agar janin dapat berkembang secara optimal serta adanya edukasi di bidang kebidanan setiap pasien ANC mendatangi poli kebidanan.

\section{BBLR}

Hasil penelitian menunjukkan bahwa hampir seluruhnya $(92,9 \%)$ bayi lahir dengan BBLR, sebagian kecil $(7,1 \%)$ lahir dengan BBLSR dan BBLER tidak ada (0\%) Hasil penelitian kelompok umur yang melahirkan BBLR menunjukkan bahwa hampir setengahnya $(47,6 \%)$ dari responden berumur 20-35 tahun, lebih dari 35 tahun (40,5\%) dan sebagian kecil $(11,9 \%)$ berumur kurang dari 20 tahun.

Penelitian yang dilakukan oleh Safitri, Wirakhmi, \& Adriani (2011) menyebutkan bahwa terjadinya BBLR dengan presentase tinggi ada pada kelompok wanita yang berusia lebih dari 40 tahun dan pada kelompok remaja kurang dari 20 tahun. Hal ini disebabkan karena pada ibu yang masih berusia remaja secara fisik sistem reproduksinya belum matang, sedangkan pada wanita yang sudah tua hal ini disebabkan karenan penurunan kondisi fisik pada sistem kesehatan reproduksi. Kedua penyebab itulah yang dapat menyebabkan terjadinya BBLR dan meningkatkan risiko

Sistriani (2008) juga menyatakan usia yang bagus untuk ibu dapat hamil adalah antara usia 20 hingga 35 tahun. Kehamilan yang terjadi ketika ibu berusia di bawah 20 tahun dan/atau di atas usia 35 tahun sangat berisiko tinggi.

Dengan lahirnya bayi dengan berat badan lahir rendah adalah belum siapnya bayi dan organ - organnya untuk hidup di luar kandungan. Selain itu bayi akan lambat dalam beradaptasi, gangguan pernafasan, mudah kehilangan panas tubuh, dan kadar gula dalam tubuh cepat menurun. Oleh sebab itu dibutuhkan observasi ketat dalam penanganan BBLR dan BBLSR agar tidak terjadi kecacatan bahkan kematian. Dengan kejadian BBLR dan BBLSR maka yang harus dilakukan ketersediaan alat incubator sebagai desain dan tempat pengganti uterus ibu. Pemenuhan kebutuhan suplai oksigen dengan menggunakan Neo-PAP. Observasi kebutuhan asupan nutrisi dimana mengutamakan pemberian ASI daripada susu formula secara rutin yaitu setiap 2 jam sekali dengan menggunakan pipet. Adanya Pelayanan Metode Kanguru (PMK) bagi keluarga yang mempunyai bayi dengan BBLR sehingga saat bayi dinyatakan boleh pulang tetap terjaga suhu tubu dan pemenuhan nutrisinya.

Bayi dengan BBLR dan BBLSR berisiko terjadinya komplikasi mulai dari system dan fungsi organ. Sehingga jika perawatan bayi BBLR dan BBLSR tidak tepat dan denga tidak melakukan observasi ketat, bayi akan mengalami depresi nafas, kehilangnan panas tubuh, gula darah yang menurun dratis, bayi kejang dan kemudian meninggal. Dengan tempat penelitian yang memiliki kriteria NICU level 2 maka Rumah Sakit Kristen Mojowarno tidak melayani bayi dengan Berat Badan Ekstrim Rendah (BBLER). Hal yang berpengaruh sangat penting yaitu ANC terpadu dan observasi ketat.,Ketika ditemukan kasus ibu yang kemungkinan melahirkan bayi dengan BBLER maka dilakukan rujukan ke Rumah Sakit level B dan dalam keadaan masih intrauterine. 


\section{Hubungan Paritas dengan BBLR}

Berdasarkan tabel 5 menunjukkan bahwa hampir setengahnya ibu primipara melahirkan bayi BBLR yaitu sebanyak 15 bayi ( $35,7 \%$ ) dan sebagian besar ibu multipara melahirkan bayi BBLR sebanyak 22 orang $(52,4 \%)$ Sedangkan berdasarkan hasil uji statistik menggunakan Spearman Rho dengan signifikansi 95\% $(\alpha=0,05)$ didapatkan nilai $r_{\text {hitung }}(0,470)$ yang berarti lebih besar daripada nilai $r$ tabel $(0,257)$ maka H1 diterima, HO ditolak, hal ini berarti ada hubungan paritas dengan berat badan lahir rendah (BBLR) di Ruang Bersalin RSUD Cendrawasih Dobo Januari - Juli Tahun 2020

Teradinya BBLR paling banyak disebabkan oleh prematuritas. Selain faktor prematuritas, penyebab BBLR yang sering adalah karena faktor ibu seperti paritas, usia ibu, dan sebagainya. Faktor lainnya yang berpengaruh yaitu kehamilan kembar, penyakit vaskuler, dan partus prematur imminens, serta faktor janin juga menyumbang angka kejadian BBLR (Pantiawati, 2010).

Secara umum, kejadian BBLR dan kematian perintal mengalami peningkatan seiring dengan peningkatan paritas ibu, apalagi jika ibu telah pernah hamil (sebanyak) lebih dari 3 kali. Paritas yang tinggi pada umumnya dapat menyebabkan terjadinya disfungsi pada pembuluh darah uterus yang dapat menyebabkan terganggunya sirkulasi darah yang mengandung oksigen dan nutrisi dari ibu ke janin sehingga dapat mempengaruhi pertumbuhan dan perkembangan janin dan diakhiri dengan terjadinya BBLR atau janin lahir mati (Winkjosastro, 2008; Wong, D. L., Hockenberry, M. E., Wilson, D., Winkelstein, M. \& Schwartz, 2009).

Hal ini sesuai dengan teori yang ada karena hampir seluruh responden yang melahirkan bayi BBLR dan BBLSR adalah ibu dengan multipara hal ini dikarenakan bukan hanya paritas yang mempengaruhi terjadinya BBLR dan BBLSR melainkan banyak hal yang dapat mempengaruhinya seperti adanya kelainan pada janin itu sendiri, penyakit yang diderita oleh ibu yaitu PEB, kehamilan ganda dan PPI, keadaan sosial ekonomi yang rendah, gaya hidup ibu saat hamil serta kurangnya pengetahuan ibu tentang hal-hal yang harus diperhatikan saat hamil. Sehingga paritas dengan multipara mempunyai kemungkinan besar melahirkan bayi BBLR dan BBLSR. Dengan lahirnya bayi BBLR maka sangat mempengaruhi psikologis ibu post partum. Selain itu perawatan bayi dengan BBLR dan BBLSR membutuhkan dana yang cukup banyak dan kemungkinan kecacatan hingga kematian cukup tinggi.

Dampak dari penyakit penyerta yang di derita ibu hamil dengan DM, hipertensi kronik, PPI, PEB adalah kelahiran dengan bayi BBLR dan BBLSR. Dalam data penelitian yang telah diambil kejadian ibu dengan DM melahirkan BBLR sebanyak 3, hipertensi kronik dengan BBLR sebanyak 1 , PPI dengan BBLR sebanyak 1 dan BBLSR sebanyak 3, PEB dengan BBLR sebanyak 4.Oleh sebab itu sangat penting pemeriksaan kehamilan dan menjaga kesehatan ibu dan janin. Perlu kerjasama yang baik antar tenaga kesehatan dalam menangani ibu hamil dengan komplikasi PEB, kehamilan ganda dan PPI. Merujuk pasien tepat pada waktunya. Serta menangani komplikasinya dengan baik demi kesejahteraan ibu dan janin. Jika bayi harus dilahirkan dalam keadaan BBLR maka terapi konservatif sangat membantu paru - paru bayi BBLR untuk beradaptasi dengan dunia luar.

\section{SIMPULAN}

Berdasarkan penelitian ini dapat disimpulkan bahwa sebagian besar ibu bersalin $(52,4 \%)$ merupakan ibu multipara. Sedangkan hampir seluruhnya $(92,9 \%)$ bayi lahir dengan keadaan BBLR (Berat Badan Lahir Rendah). Berdasarkan hasil ujistatistik didapatkan kesimpulan bahwa terdapat hubungan antara paritas dengan Berat Badan Lahir Rendah (BBLR).

Beberapa hal yang dapat dilakukan dalam rangka menekan angka kejadian BBLR adalah dengan mengedukasi ibu melalui 
penyuluhan kesehatan dengan memberikan informasi kepada ibu selama hamil, baik saat kelas ibu hamil dan/atau saat dilakukan kunjungan antenatal.

\section{UCAPAN TERIMAKASIH}

Tim peneliti mengucapkan terimakasih kepada Direktur RSUD Cendrawasih Dobo beserta seluruh staf dan tenaga medis yang telah membantu peneliti demi terlaksananya dan lancarnya seluruh rangkaian penelitian ini.

\section{DAFTAR PUSTAKA}

Badan Pusat Statistik, Badan Koordinasi Keluarga Berencanan Nasional, Departemen Kesehatan, \& Macro International. (2013). Survei Demografi dan Kesehatan Indonesia 2012. Sdki, 16. https://doi.org/10.1111/j.14710528.2007.01580.x

Balitbang Kemkes RI. (2019). Laporan Nasional RISKESDAS 2018. Jakarta.

Bambang, R., Khasanah, U., \& Khoirotul, H. (2011). Hubungan antara Usia Ibu dan Paritas dengan Kejadian Berat Badan Lahir Rendah (BBLR) di RSU Dr. Saiful Anwar Malang. Universitas Brawijaya Malang.

DEPKES RI. (2001). Angka Kematian Ibu dan Angka Lematian Bayi. Retrieved from http:/www.Litbang.depkes.go.id

Dinkes Maluku. (2019). Laporan Bulanan 3 (LB3) Kesehatan Ibu dan Anak 2019. Maluku.

Evasari, E., \& Nurmala, E. (2016). Hubungan Umur, Paritas dan Status Gizi Ibu dengan Kejadian BBLR. Jurnal Obstretika Scientia, 4(2), 453-471.

Pantiawati, I. (2010). Bayi dengan BBLR. Yogyakarta: Nuha Medika.

Prawirohardjo, S. (2010). Ilmu Kebidanan. Jakarta: PT Bina Pustaka.
Safitri, A. D., Wirakhmi, I. N., \& Adriani, P. (2011). Hubungan Antara Kehamilan usia Dini dengan Kejadian Berat Bayi Lahir Rendah (BBLR) di RSUD Dr. R. Goeteng Taroenadibrata Tahun 2011. Jurnal Kesehatan, 12, 50-63.

Sistriani, C. (2008). Faktor Maternal dan Kualitas Pelayanan Antenatal yang Berisiko terhadap Kejadian Bayi Berat Lahir Rendah (BBLR) Studi pada Ibu yang Periksa Hamil Ke Tenaga Kesehatan dan Melahirkan di RSUD Banyumas. Univesitas Diponegoro.

UNICEF Indonesia. (2019). Situasi Anak di Indonesia. Retrieved from UNICEF Indonesia website: www.unicef.org

Winkjosastro, H. (2008). Ilmu Kebidanan. Jakarta: Yayasan Bina Pustaka Sarwono Prawiroharjo.

Wong, D. L., Hockenberry, M. E., Wilson, D., Winkelstein, M. \& Schwartz, P. (2009). Buku Ajar Keperawatan Pediatrik (6th ed.). Jakarta: EGC. 